\title{
Piperlongumine induces autophagy in biliary cancer cells via reactive oxygen species-activated Erk signaling pathway
}

\author{
SAN-YUAN CHEN ${ }^{1,2}$, HSIN-YI HUANG ${ }^{1,3}$, HAN-PEI LIN $^{3}$ and CHIUNG-YAO FANG ${ }^{3}$ \\ ${ }^{1}$ Department of Chinese Medicine, Ditmanson Medical Foundation Chiayi Christian Hospital, Chiayi 600; \\ ${ }^{2}$ Department of Sports Management, Chia Nan University of Pharmacy and Science, Tainan 717; ${ }^{3}$ Department of \\ Medical Research, Ditmanson Medical Foundation Chiayi Christian Hospital, Chiayi 600, Taiwan, R.O.C.
}

Received January 21, 2019; Accepted August 2, 2019

DOI: $10.3892 / \mathrm{ijmm} .2019 .4324$

\begin{abstract}
Biliary cancer (BC) is an aggressive neoplasm with high mortality. BC can be categorized into three groups: Intrahepatic cholangiocarcinoma (CCA; also known as bile duct cancer), extrahepatic cholangiocarcinoma and gallbladder cancer. Due to its heterogeneity and aggressiveness, the response to current chemotherapy and radiotherapy methods in patients with $\mathrm{BC}$ is poor. Therefore, there is an urgent requirement to develop drugs to treat BC. Piperlongumine (PL), a naturally occurring small molecule isolated from Piper longum L., exhibits anticancer activity by inducing reactive oxygen species (ROS) production. In the present study, the effects of PL on cell proliferation, cell cycle, apoptosis and autophagy in BC cells were investigated. PL induced BC cell death in a concentration- and time-dependent manner by inducing ROS production. PL induced cell cycle arrest in CCA cells (HuCCT-1) and gallbladder cancer cells (OCUG-1) cells, but with distinct cell cycle distribution profiles. PL caused G2/M cell cycle arrest in HuCCT-1 cells, and G0/G1 cell cycle arrest in OCUG-1 cells. PL induced apoptosis and autophagy; PL treatment induced accumulation of LC3-II in a concentration- and time-dependent manner. The Erk signaling pathway appeared to be involved in autophagy induction. Application of the ROS scavenger, $\mathrm{N}$-acetyl-1-cysteine, to BC cells attenuated the cell death, cell cycle arrest, apoptosis and autophagy induced by PL treatment. These findings indicated that PL may be a potential agent for $\mathrm{BC}$ treatment in the future.
\end{abstract}

Correspondence to: Dr Chiung-Yao Fang, Department of Medical Research, Ditmanson Medical Foundation Chiayi Christian Hospital, 539 Chung Hsiao Road, Chiayi 600, Taiwan, R.O.C. E-mail: fcyo@ms72.hinet.net

Key words: cholangiocarcinoma, piperlongumine, reactive oxygen species, autophagy, Erk signaling

\section{Introduction}

Biliary cancer (BC) is an aggressive neoplasm with high mortality. Although the incidence of $\mathrm{BC}$ is relatively low, it is increasing $(1,2)$. Based on its anatomical origin, $\mathrm{BC}$ can be categorized as intrahepatic or extrahepatic cholangiocarcinoma (CCA), or gallbladder cancer (3). The treatment options for BC include surgery, chemotherapy and radiation therapy (4). Surgery is the most curative therapy for BC, but most patients present an advanced disease stage at diagnosis and are not suitable for surgical resection (5). Furthermore, numerous patients exhibit recurrent $\mathrm{BC}$ even following complete surgical resection (4). Several drugs are now used for adjuvant or systemic chemotherapy in patients with advanced or recurrent $\mathrm{BC}$ (6); a regimen based on the combination of gemcitabine and cisplatin is regarded as a first-line treatment for patients with advanced BC. Studies have shown a survival benefit for patients with $\mathrm{BC}$ after receiving chemotherapy $(7,8)$. However, owing to its heterogeneity and aggressiveness, the overall 5-year survival rate remains low (9). Therefore, there is an urgent requirement to develop novel therapeutic medicines for BC treatment.

Reactive oxygen species(ROS) are active oxygen-containing molecules that have long been considered as by-products of cellular metabolism $(10,11)$. ROS can be produced by mitochondrial respiration, the NADPH oxidase complex and other biochemical reactions $(6,10)$. Excessive ROS production may be harmful to cells, resulting in oxidative damage to DNA, proteins and lipids, as well as genetic instability (11). Elevated ROS levels are often observed in cancer cells (12), which may be due to the compromised ROS-scavenging ability of these cells (13). Increased ROS levels can drive abnormal proliferation of cancer cells. Simultaneously, elevated ROS levels increase the sensitivity of these cancer cells to cell death, making them more vulnerable to ROS induction (14). Therefore, a strategy to induce anticancer effects is increasing ROS levels to selectively kill cancer cells without causing damage to normal cells $(9,15)$. Recently, ROS-inducing drugs have been investigated to target various cancer cells, including colon cancer (16), prostate cancer (17), pancreatic cancer (18) and glioblastoma (19) cells. Due to the heterogeneity of $\mathrm{BC}$, drugs targeting the signaling pathways of $\mathrm{BC}$ cells are not currently available. Increased ROS production has been 
reported in BC cells (20). Thus, it is important to develop drugs that can induce ROS levels to interfere with the redox balance in $\mathrm{BC}$ cells.

Piperlongumine (PL) is a natural product isolated from the long pepper, Piper longum L. PL induces high levels of ROS production (21). It possesses selective anticancer activity in colon, ovarian, prostate, breast, pancreatic, head and neck, and renal cancers via multiple signaling pathways, including the $\mathrm{p} 38 / \mathrm{JNK}$, MAPK-C/EBO homologous protein and NF- $\mathrm{\kappa B}$ signaling pathways $(20,22-24)$, causing apoptosis or autophagy in cancer cells. However, whether PL can induce autophagy in BC cells is yet to be determined. In this study, the cytotoxic effects of PL in BC cells were investigated. In addition, autophagy in PL-treated cells was assessed, and the underlying signaling pathways induced by PL treatment were explored.

\section{Materials and methods}

Cell lines and cell culture. The human biliary epithelial tumor cell line HuCCT-1 and the gallbladder carcinoma cell line OCUG-1 were obtained from the Japanese Collection of Research Bioresources Cell Bank. HuCCT-1 and OCUG-1 cells were cultured in RPMI 1640 medium (Gibco; Thermo Fisher Scientific, Inc.) and Dulbecco's Modified Eagle's medium (Gibco; Thermo Fisher Scientific, Inc.), respectively, both containing 10\% fetal bovine serum (FBS; Gibco; Thermo Fisher Scientific, Inc.), and antibiotic and antimycotic solution (penicillin, $10 \mathrm{U} / \mathrm{ml}$; streptomycin sulfate, $10 \mu \mathrm{g} / \mathrm{ml}$; amphotericin B, $25 \mathrm{ng} / \mathrm{ml}$ ). These cell lines were tested for the absence of mycoplasma contamination. The cells were incubated in a humidified atmosphere containing $5 \% \mathrm{CO}_{2}$ at $37^{\circ} \mathrm{C}$.

Reagents and antibodies. PL was purchased from Cayman Chemical Company. Proteins were extracted with M-PER mammalian protein extraction reagent buffer (Thermo Fisher Scientific, Inc.) for western blotting. Protease inhibitor was purchased from EMD Millipore. Primary antibodies for caspase 3 (polyclonal, rabbit anti-human; 1:1,500; cat. no. 9662S), PARP (monoclonal, rabbit anti-human; 1:1,000; cat no. 9532S), cdc25C (monoclonal, rabbit anti-human; 1:1,000; cat. no. 4688S), cdc2 (monoclonal, rabbit anti-human; 1:1,000; cat. no. 9116S), cyclin D1 (monoclonal, mouse anti-human; 1:2,000; cat. no. 2926S), cyclin-dependent kinase (CDK)2 (monoclonal, rabbit anti-human; 1:1,000; cat. no. 2546S), P21 (monoclonal, rabbit anti-human; 1:1,000; cat. no. 2947S), P27 (monoclonal, rabbit anti-human; 1:1,000; cat. no. 3688S), phosphorylated (p)-Erk1/2 [monoclonal, rabbit anti-human (Thr202/Tyr204); 1:1,000; cat. no. 4377S], and Erk1/2 (monoclonal, rabbit anti-human; 1:1,000; cat. no. 4695S) were all purchased from Cell Signaling Technology, Inc. Antibodies against cyclin B1 (polyclonal, rabbit anti-human; 1:1,000; cat. no. GTX100911), cyclin A2 (polyclonal, rabbit anti-human; 1:1,000; cat. no. GTX103042), cyclin E1 (polyclonal, rabbit anti-human; 1:1,000; cat. no. GTX103045) and CDK4 (polyclonal, rabbit anti-human; 1:1,000; cat. no. GTX102993) were obtained from GeneTex, Inc. The antibody against autophagy-related protein, -Microtubule-associated protein 1A/1B light chain 3B (LC-3) antibody (polyclonal, rabbit anti-human; 1:1,000; cat. no. AP1802A) was obtained from Abgent, Inc. $\beta$-actin or GAPDH expression was used as an internal control for western blotting. The antibody against $\beta$-actin (monoclonal, mouse anti-human; 1:7,500; cat. no. sc-47778) was purchased from Santa Cruz Biotechnology, Inc. The antibody against GAPDH (monoclonal, rabbit anti-human; 1:1,000; cat. no. 2118S) was purchased from Cell Signaling Technology, Inc. $N$-acetyl-L-cysteine (NAC) and 2',7'-dichlorodihydrofluorescein diacetate $\left(\mathrm{H}_{2} \mathrm{DCFDA}\right)$ were purchased from Sigma-Aldrich (Merck KGaA). PD98059 (cat. no. 9900; Cell Signaling Technology, Inc.), an inhibitor of mitogen-activated protein kinase (MAPK) kinase (MEK1) activation and the MAPK cascade, was used in the experiment. For experiments involving this inhibitor, HuCCT-1 cells were pretreated in the presence or absence of PD98059 (20 or $30 \mu \mathrm{M})$ at $37^{\circ} \mathrm{C}$ for $1 \mathrm{~h}$ in a humidified incubator, followed by PL treatment (5 or $7.5 \mu \mathrm{M}$ for western blotting; 10 or $20 \mu \mathrm{M}$ for ROS analysis) for $24 \mathrm{~h}$. Cells were then harvested for analyses.

ROS analysis. To determine the ROS level in BC cells, $1 \times 10^{6}$ cells were seeded in 6 -well plates. The cells were pretreated with NAC $(3 \mathrm{mM})$ or DMSO in a humidified incubator at $37^{\circ} \mathrm{C}$ for $1 \mathrm{~h}$. Then, the cells were treated with $10 \mu \mathrm{M}$ $\mathrm{CM}-\mathrm{H}_{2} \mathrm{DCFDA}$, incubated at $37^{\circ} \mathrm{C}$ in the dark for $30 \mathrm{~min}$. Cells were treated with various concentrations of PL (10 or $20 \mu \mathrm{M}$ for HuCCT-1 cells; 30 or $60 \mu \mathrm{M}$ for OCUG-1 cells) in a humidified incubator at $37^{\circ} \mathrm{C}$ for $1 \mathrm{~h}$. After washing the cells, cells were trypsinized and the ROS level was determined by using flow cytometry (FACSCanto II; BD Biosciences) and analyzed by BD FACSDiva software (v6.1.3; BD Biosciences).

Cell viability analysis and colony formation assay. Cell viability was determined by using a Cell Counting Kit-8 (CCK-8) proliferation assay (Sigma-Aldrich; Merck KGaA) according to the manufacturer's protocols. The absorbance values were read at $490 \mathrm{~nm}$ at $2 \mathrm{~h}$ following the addition of CCK- 8 reagent. Briefly, $1 \times 10^{4}$ HuCCT- 1 cells were seeded in 96-well plates, pretreated with NAC as aforementioned and then treated with $2.5,5$ or $10 \mu \mathrm{M} \mathrm{PL}$, and incubated for 24 and $48 \mathrm{~h}$ at $37^{\circ} \mathrm{C}$ in a humidified incubator, at which point $100 \mu \mathrm{l}$ CCK-8 reagent (mixed 1:20 in medium) was added to each well. The values of vehicle-treated cells were used for normalization. Three independent experiments were conducted. The assay protocol for OCUG-1 cells was the same, except for the concentration of PL $(5,10$ or $20 \mu \mathrm{M})$. For the colony formation assay, $1 \times 10^{3}$ cells were seeded in 6-well plates. At day 7 after cell plating, the cells were washed and fixed with $10 \%$ formaldehyde at $25^{\circ} \mathrm{C}$ for $10 \mathrm{~min}$, and stained with $0.05 \%$ crystal violet (Sigma-Aldrich; Merck $\mathrm{KGaA}$ ) at $25^{\circ} \mathrm{C}$ for $15 \mathrm{~min}$. The colonies were scanned and analyzed with ImageJ software (FiJi-win32; National Institutes of Health).

Cell cycle analysis. For determination of cell cycle profile, $1 \times 10^{5}$ cells were seeded in 6-well plates. After serum starvation for $24 \mathrm{~h}$, the cells were treated with PL (5 or $10 \mu \mathrm{M}$ for HuCCT-1 cells; 15 or $30 \mu \mathrm{M}$ for OCUG-1 cells) and/or NAC as aforementioned and harvested at 24 and $48 \mathrm{~h}$. The cells were then fixed by using $100 \%$ methanol for $24 \mathrm{~h}$ at $4^{\circ} \mathrm{C}$. Propidium iodide (PI; $0.05 \mathrm{mg} / \mathrm{ml}$ ) solution containing RNase was added to the methanol-fixed cells. The cells were then incubated at $25^{\circ} \mathrm{C}$ in the dark for $30 \mathrm{~min}$. The DNA content was analyzed 
by performing flow cytometry to determine the percentage of cells in each phase of the cell cycle using Modfit LT 3.3 cell cycle analysis software (Verity Software House).

Detection of apoptosis by flow cytometric analysis. The percentage of apoptotic cells was determined after PL treatment. The cells were treated with PL for 24 and $48 \mathrm{~h}$, harvested and subjected to Annexin V and PI staining (5 $\mu \mathrm{l}$ Annexin V-FITC and $5 \mu \mathrm{l}$ PI in $500 \mu$ l binding buffer) at $25^{\circ} \mathrm{C}$ for $5 \mathrm{~min}$ in the dark using an apoptosis detection kit (BioVision, Inc.). Apoptotic cells were determined using flow cytometry (FACSCanto II; BD Biosciences) and analyzed using BD FACSDiva software (v6.1.3). The apoptotic ratio was calculated based on the percentage early + late apoptotic cells

Cell lysate preparation and western blotting. Cells were lysed and extracted by using M-PER mammalian protein extraction reagent (Thermo Fisher Scientific, Inc.) containing protease inhibitor cocktail (Cell Signaling Technology, Inc.). Bio-Rad Protein Assay reagent (Bio-Rad Laboratories, Inc.) was used to determine the concentration of extracted protein. Protein (40 $\mu \mathrm{g} /$ lane) was subjected to $12.5 \%$ SDS-PAGE and electrotransferred onto a polyvinylidene difluoride membrane (Bio-Rad Laboratories, Inc.). The membrane was blocked by incubation with 5\% skim milk (Sigma-Aldrich; Merck KGaA) at $25^{\circ} \mathrm{C}$ for $1 \mathrm{~h}$, followed by probing with specific primary antibodies at $4^{\circ} \mathrm{C}$ for $16 \mathrm{~h}$. The membrane was then incubated with horseradish peroxidase-conjugated goat anti-rabbit IgG (1:5,000; cat. no. 111-035-003) or goat anti-mouse IgG (1:5,000; cat. no. 115-035-003) secondary antibodies (Jackson ImmunoResearch Laboratories, Inc.) for $2 \mathrm{~h}$ at $25^{\circ} \mathrm{C}$. Protein expression was detected using an enhanced chemiluminescence horseradish peroxidase substrate detection kit (cat. no. WBKLS0500; EMD Millipore) and quantified using a UVP BioSpectrum 800 Imaging System (UVP, LLC).

Immunofluorescence assay. HuCCT-1 cells cultured on coverslips were fixed with ice-cold acetone and methanol (2:1) at $-20^{\circ} \mathrm{C}$ for $30 \mathrm{~min}$ and were then blocked with $5 \%$ normal horse serum (Gibco; Thermo Fisher Scientific, Inc.) in phosphate-buffered saline (PBS) for $30 \mathrm{~min}$ at $25^{\circ} \mathrm{C}$. The cells were then washed with PBS and incubated for $16 \mathrm{~h}$ at $4^{\circ} \mathrm{C}$ with LC-3 antibody (1:100 in 5\% normal horse serum). After washing with PBS, the cells were incubated with goat ant-rabbit IgG secondary antibody conjugated with Alexa Fluor ${ }^{\circledR} 488$ (1:7,500; cat. no. A-11008; Invitrogen; Thermo Fisher Scientific, Inc.) for $1 \mathrm{~h}$ at $25^{\circ} \mathrm{C}$. Next, the cells were washed again with PBS and stained with $1 \mu \mathrm{g} / \mathrm{ml}$ DAPI in PBS at $25^{\circ} \mathrm{C}$ for $5 \mathrm{~min}$. The coverslips were mounted with anti-fading solution (Sigma-Aldrich; Merck KGaA) and examined under fluorescence microscopy (magnification, 200; Olympus 1X81; Olympus Corporation).

Statistical analysis. Statistical significance was determined using the GraphPad Prism 5.0 software (GraphPad Software, Inc.). The data were analyzed using two-way analysis of variance followed by Bonferroni post hoc test for multiple comparisons. All in vitro experiments were repeated three times and the results are presented as means \pm SD. $\mathrm{P}<0.05$ was considered to indicate a statistically significant difference.

\section{Results}

PL exhibits growth inhibitory activity against BC cells, which is attenuated by a ROS inhibitor. To determine the inhibitory effects of PL on BC cell proliferation, HuCCT-1 and OCUG-1 cells were treated with different concentrations of PL for 24 and $48 \mathrm{~h}$. Cell survival rates were analyzed using a CCK-8 assay. PL treatment produced a significant cytotoxic effect on both HuCCT-1 (Fig. 1A) and OCUG-1 (Fig. 1B) cells. HuCCT-1 exhibited greater sensitivity to PL treatment, with $\mathrm{IC}_{50}$ values of 24.8 and $4.2 \mu \mathrm{M}$ at 24 and $48 \mathrm{~h}$, respectively. The $\mathrm{IC}_{50}$ of PL for OCUG-1 cells at 24 and $48 \mathrm{~h}$ was 22.2 and $13.8 \mu \mathrm{M}$, respectively. Cell proliferation was then evaluated using a clonogenic assay. As shown in Fig. 1C and D, PL treatment decreased the colony number in a concentration-dependent manner, and HuCCT-1 cells exhibited a more pronounced response to PL treatment than OCUG-1 cells.

It was then determined whether the cytotoxicity of PL to HuCCT-1 and OCUG-1 cells was due to an imbalance in redox status. ROS levels were measured via flow cytometric analysis in PL-treated cells in the presence or absence of the ROS scavenger NAC. The data from cytometric analysis demonstrated that PL treatment increased ROS levels in a concentration-dependent manner (Fig. S1). Furthermore, the reduction in ROS levels was associated with the rescue of cell death in NAC-treated cells (Fig. 1). The reversal of cell death by NAC showed a significant difference, most notably in high-concentration PL-treated cells and those treated with PL for a long duration. Collectively, these data suggested that PL exhibits substantial cytotoxicity by interfering with the redox balance in HuCCT-1 and OCUG-1 cells.

$P L$ interferes with cell cycle progression in $\mathrm{HuCCT-1}$ and OCUG-1 cells. To determine the mechanism underlying the antiproliferative effects of PL, the cell cycle distribution profiles of HuCCT-1 and OCUG-1 cells following PL treatment were determined via flow cytometric analysis. As shown in Fig. 2A, HuCCT-1 cells showed G2/M phase arrest after PL treatment. The G2/M cell distribution was increased from $20.8 \pm 2.8$ and $14.3 \pm 1.1 \%$ in the vehicle control group to $45.4 \pm 6.8$ and $30.3 \pm 7.0 \%$ in $5 \mu \mathrm{M}$ PL-treated HuCCT-1 cells after treatment for 24 and $48 \mathrm{~h}$, respectively. In contrast, OCUG-1 cells exhibited G0/G1 phase arrest after PL treatment (Fig. 2B). The G0/G1 cell distribution increased from $46.8 \pm 1.5$ and $63.3 \pm 0.4 \%$ in the vehicle control group to $87.5 \pm 0.62$ and $75.1 \pm 1.5 \%$ in $15 \mu \mathrm{M}$ PL-treated OCUG-1 cells after treatment for 24 and $48 \mathrm{~h}$, respectively. Similar cell cycle arrest was observed in 10 and $30 \mu \mathrm{M}$ PL-treated HuCCT-1 and OCUG-1 cells. Pretreatment with NAC partially reversed the cell cycle arrest induced by PL in both HuCCT-1 and OCUG-1 cells. Additionally, an increase in the sub-G1 cell population was observed with higher PL concentrations and longer exposure time (48 h). Pretreatment with NAC decreased the sub-G1 cell population induced by PL in both HuCCT-1 and OCUG-1 cells. These data suggested that cell cycle arrest was associated with the antiproliferative effects induced by PL treatment in HuCCT-1 and OCUG-1 cells.

To further verify the induction of cell cycle arrest by PL, the expression of cell cycle-associated checkpoint proteins was analyzed via western blotting. $\mathrm{Cdc} 25 \mathrm{C}$ is a key protein in 
A
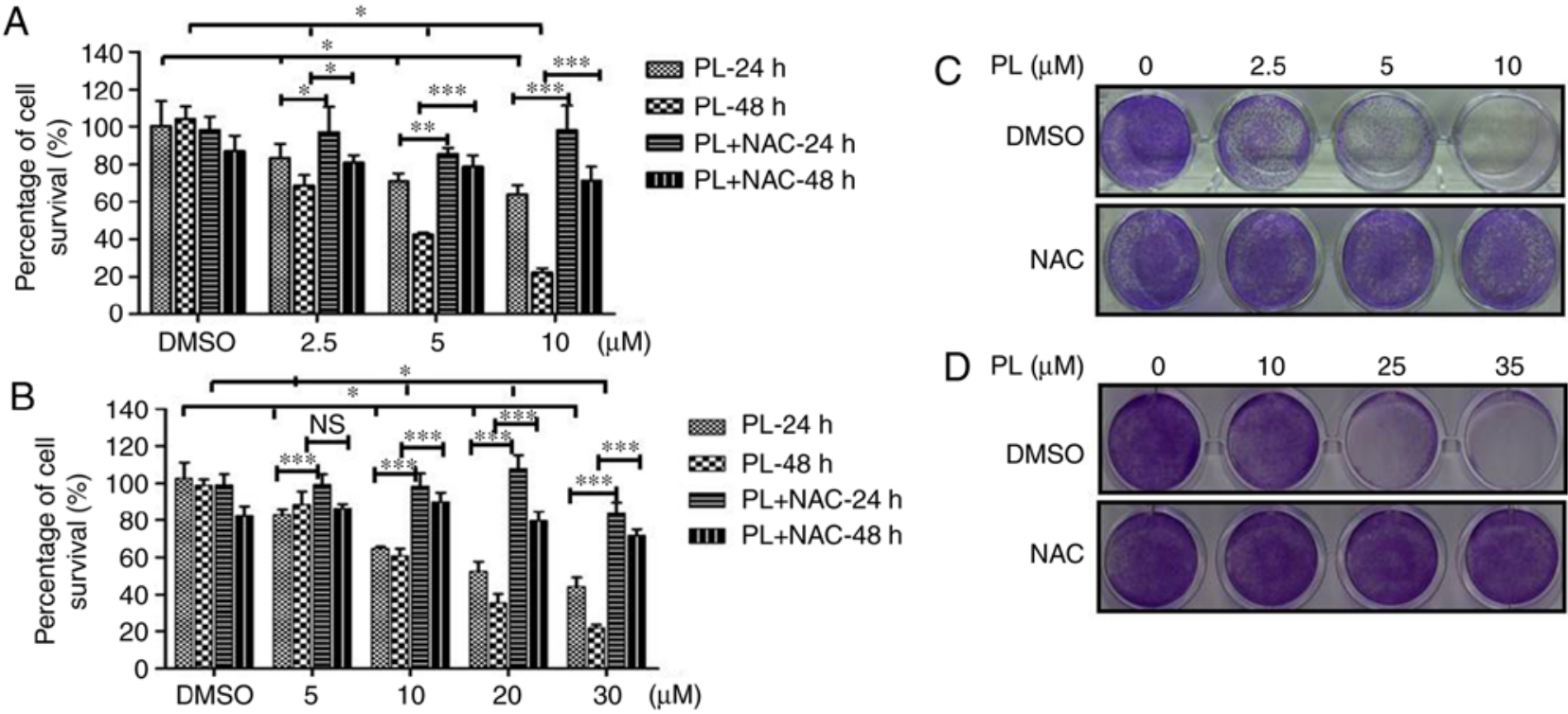

Figure 1. Cytotoxic effects of PL on biliary cancer cells. (A) HuCCT-1 and (B) OCUG-1 cells were treated with the indicated concentrations of PL for 24 or $48 \mathrm{~h}$ with or without NAC pretreatment. Cell viability was determined by a Cell Counting Kit- 8 assay, and is presented as the percentage of cell survival. Data are presented as the mean $\pm \mathrm{SD}$ of at least three independent experiments. ${ }^{*} \mathrm{P}<0.05,{ }^{* *} \mathrm{P}<0.01,{ }^{* * * *} \mathrm{P}<0.001$. (C) HuCCT-1 and (D) $\mathrm{OCUG}-1$ cells were treated with the indicated concentrations of PL for 7 days. The cells were then fixed and stained with crystal violet. PL, piperlongumine; NAC, $N$-acetyl-1-cysteine.

regulating cell cycle entry into mitosis (25). Cyclin B1-cdc2 complex activation controls cell cycle mitotic progression (26). Cyclin A2 is involved in G2/M transition (22). As shown in Fig. 3A, treatment with PL reduced the protein levels of cdc25C, cyclin B1, cdc2 and cyclin A2 in HuCCT-1 cells. Similarly, the decrease in the expression of these $\mathrm{G} 2 / \mathrm{M}$-regulating proteins induced by PL was attenuated by NAC pretreatment (Fig. 3A).

The proteins p21 and p27 are cyclin-dependent kinase inhibitors that bind to and inhibit the activity of CDK2, CDK1 and CDK4/6 complexes; both $\mathrm{p} 21$ and $\mathrm{p} 27$ are thus regarded as regulators of cell cycle progression to G1 phase (27). The results of western blotting showed that PL treatment increased the expression of $\mathrm{p} 21$ and $\mathrm{p} 27$ proteins, and decreased the expression of cyclin E1/D2 and CDK2/4 in OCUG-1 cells (Fig. 3B). This finding indicated that PL treatment induces G0/G1 cell cycle arrest in OCUG-1 cells. Similar to that in HuCCT-1 cells, G0/G1 cell cycle arrest induced by PL in OCUG-1 cells can be reversed by NAC treatment (Fig. 3B).

$P L$ induces apoptosis and autophagy in HuCCT-1 and OCUG-1 cells. Whether PL can induce apoptotic cell death in BC cells was further analyzed. HuCCT-1 and OCUG-1 cells were treated with different concentrations of PL for $48 \mathrm{~h}$. Apoptotic cells were determined via flow cytometry using Annexin V/PI double staining. As presented in Fig. 4A and B, $\mathrm{PL}$ treatment resulted in increased Annexin-V staining in a concentration-dependent manner, which indicates apoptotic cell death. The apoptotic ratio in HuCCT-1 cells was $10.6 \pm 3.3 \%$ at $5 \mu \mathrm{M}$ and $26.0 \pm 4.9 \%$ at $10 \mu \mathrm{M}$ PL vs. $4.7 \pm 1.4 \%$ in the vehicle control cells. The apoptotic ratio in OCUG-1 cells was $30.9 \pm 6.3 \%$ at $15 \mu \mathrm{M}$ and $55.1 \pm 4.5 \%$ at $30 \mu \mathrm{M} \mathrm{PL}$ vs. $28.3 \pm 3.4 \%$ in the vehicle control cells. When the cells were pretreated with NAC, the apoptotic ratio decreased from $26.0 \pm 4.9$ to $6.1 \pm 2.1 \%$ and $55.1 \pm 4.5$ to $20.8 \pm 2.3 \%$ in HuCCT- 1 and OCUG-1 cells, respectively. Western blotting was then performed to determine whether caspases were involved in PL-induced apoptosis. However, only a faint increase in caspase 3 cleavage was observed in HuCCT-1 cells (Fig. 5A), with no clear increase in OCUG-1 cells after PL treatment, as determined via western blot analysis (Fig. 5B). Similar to the results of caspase 3 cleavage, no clear increase in PARP cleavage was detected after PL treatment (Fig. 5A and B).

During autophagy, cytoplasmic LC3-I is conjugated to phosphatidyl ethanolamine to form LC3-II (28). As shown in Fig. 5A and B, LC3-II expression increased after PL treatment in HuCCT-1 and OCUG-1 cells. A reduction in LC3-II expression was observed when the cells were pretreated with NAC prior to PL application.

$P L$ induces autophagy via ROS-activated Erk signaling pathway. An increase in LC3-II suggests that PL treatment induces autophagy in HuCCT-1 and OCUG-1 cells. Therefore, the pathways involved in this activation were investigated. As shown in Fig. 6A, Erk phosphorylation increased after PL treatment, indicating that PL activated the Erk pathway in HuCCT-1 cells. However, Erk phosphorylation was not observed in OCUG-1 cells at $48 \mathrm{~h}$ after PL treatment (Fig. 6B). These results indicated that PL activated the Erk pathway in HuCCT-1 cells, but only transiently in OCUG-1 cells. Pretreatment with NAC decreased p-Erk levels in HuCCT-1 cells only, without affecting total Erk expression, suggesting that activation of the Erk signaling pathway occurs via ROS induction in PL-treated HuCCT-1 cells. Erk phosphorylation occurred concomitantly with an increase in LC3-II expression, and the reduction in p-Erk levels with NAC pretreatment was concomitant with the reduction in LC3-II (Fig. 6A). Conversely, NAC pretreatment did notably reduce Erk phosphorylation in OCUG-1 cells (Fig. 6B). During autophagy, LC3-II aggregates and is recruited to the autophagosomal membrane (28). Aggregated LC3-II, termed LC3 puncta, can 
A

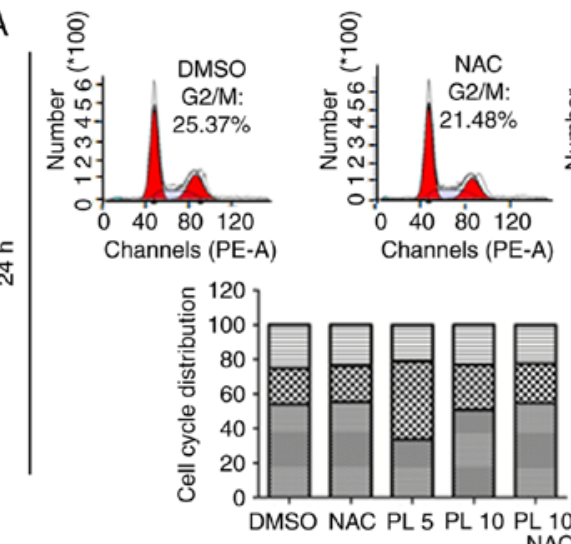

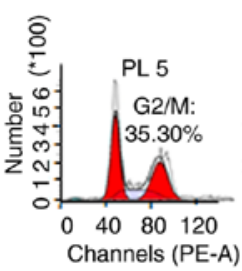
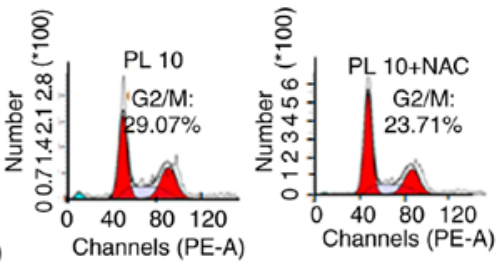

G0/G1

G2/M

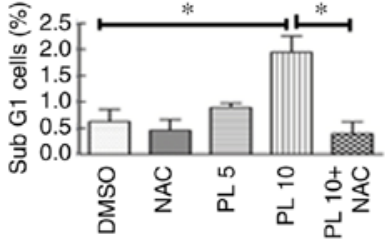

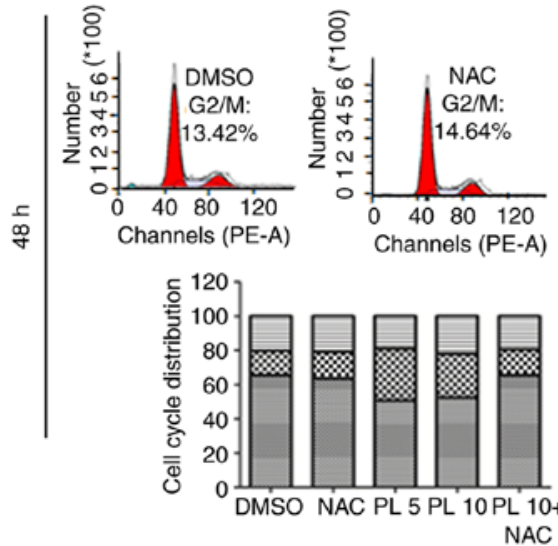
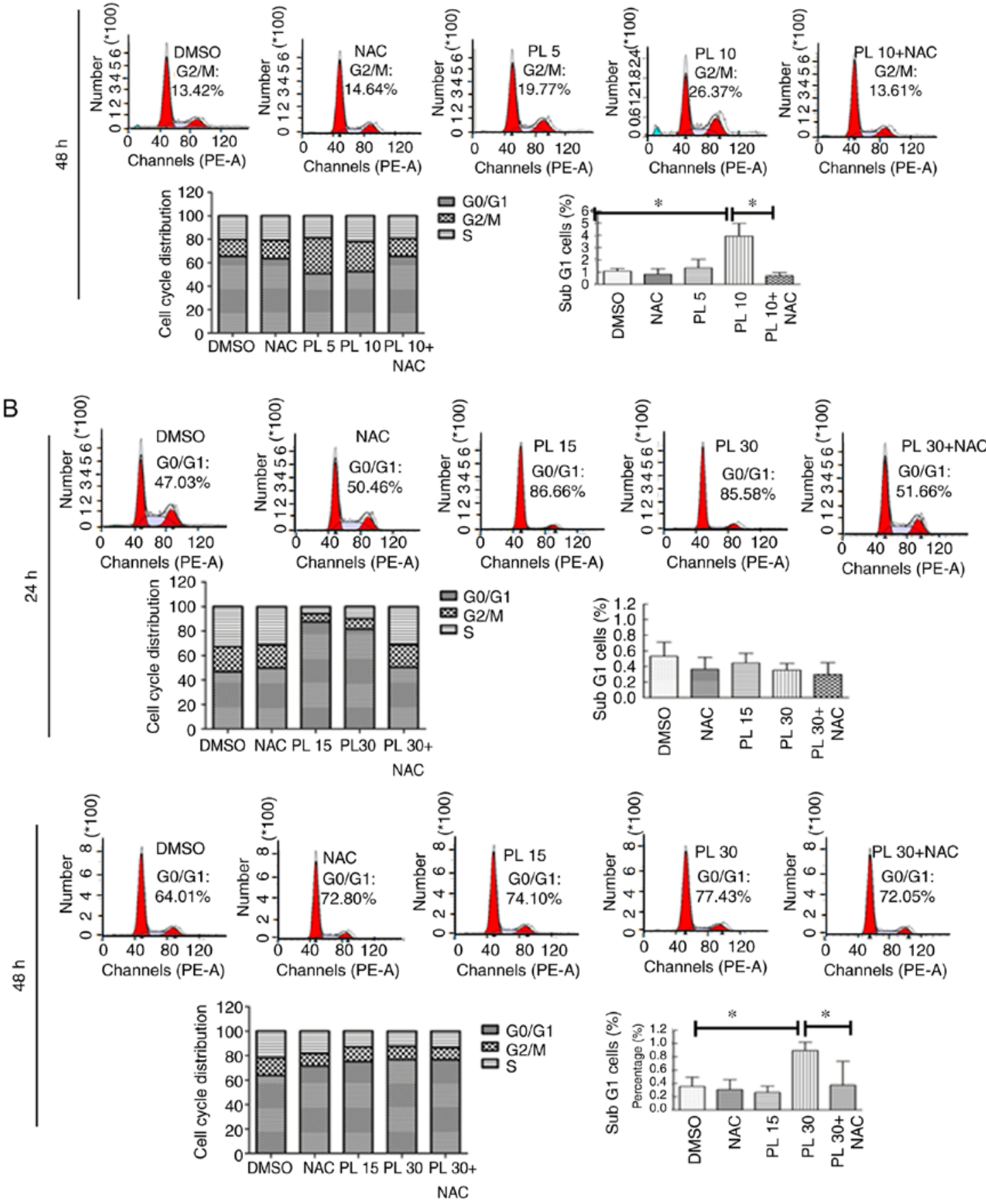

Figure 2. PL induces cell cycle arrest in biliary cancer cells. (A) HuCCT-1 and (B) OCUG-1 cells were treated with the indicated concentrations of PL for 24 or $48 \mathrm{~h}$ with or without NAC pretreatment. Cell cycle distribution was analyzed by flow cytometry. The Sub-G1 cell population was determined after flow cytometric analysis. PL concentrations are in $\mu \mathrm{M}$. Data are presented as the mean $\pm \mathrm{SD}$ of at least three independent experiments. ${ }^{*} \mathrm{P}<0.05$. PL, piperlongumine; NAC, $N$-acetyl-l-cysteine. 
A

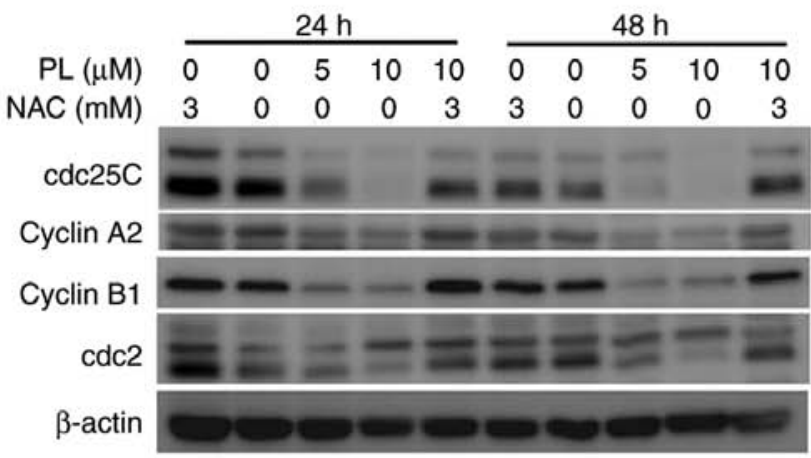

B

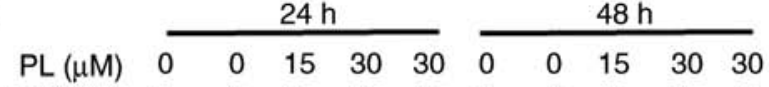

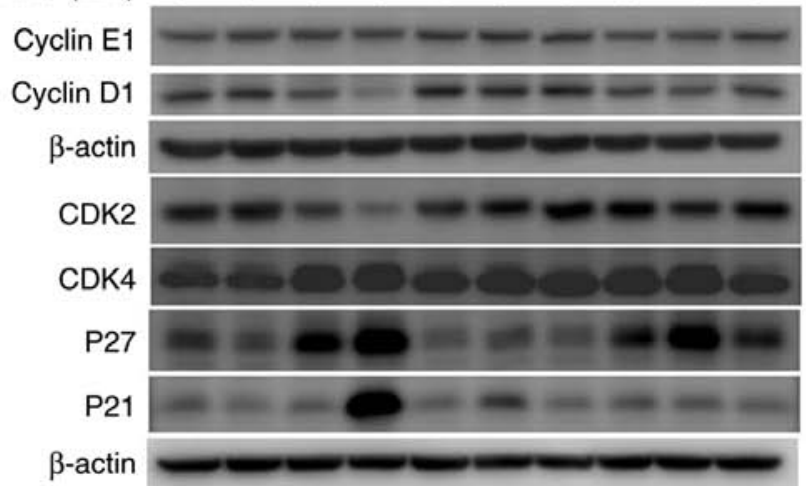

Figure 3. PL induces altered expression of cell cycle-associated proteins in biliary cancer cells. (A) HuCCT-1 and (B) OCUG-1 cells were treated with the indicated concentrations of PL for 24 or $48 \mathrm{~h}$ with or without NAC pretreatment. CDK, cyclin-dependent kinase; PL, piperlongumine; NAC, $N$-acetyl-1-cysteine.
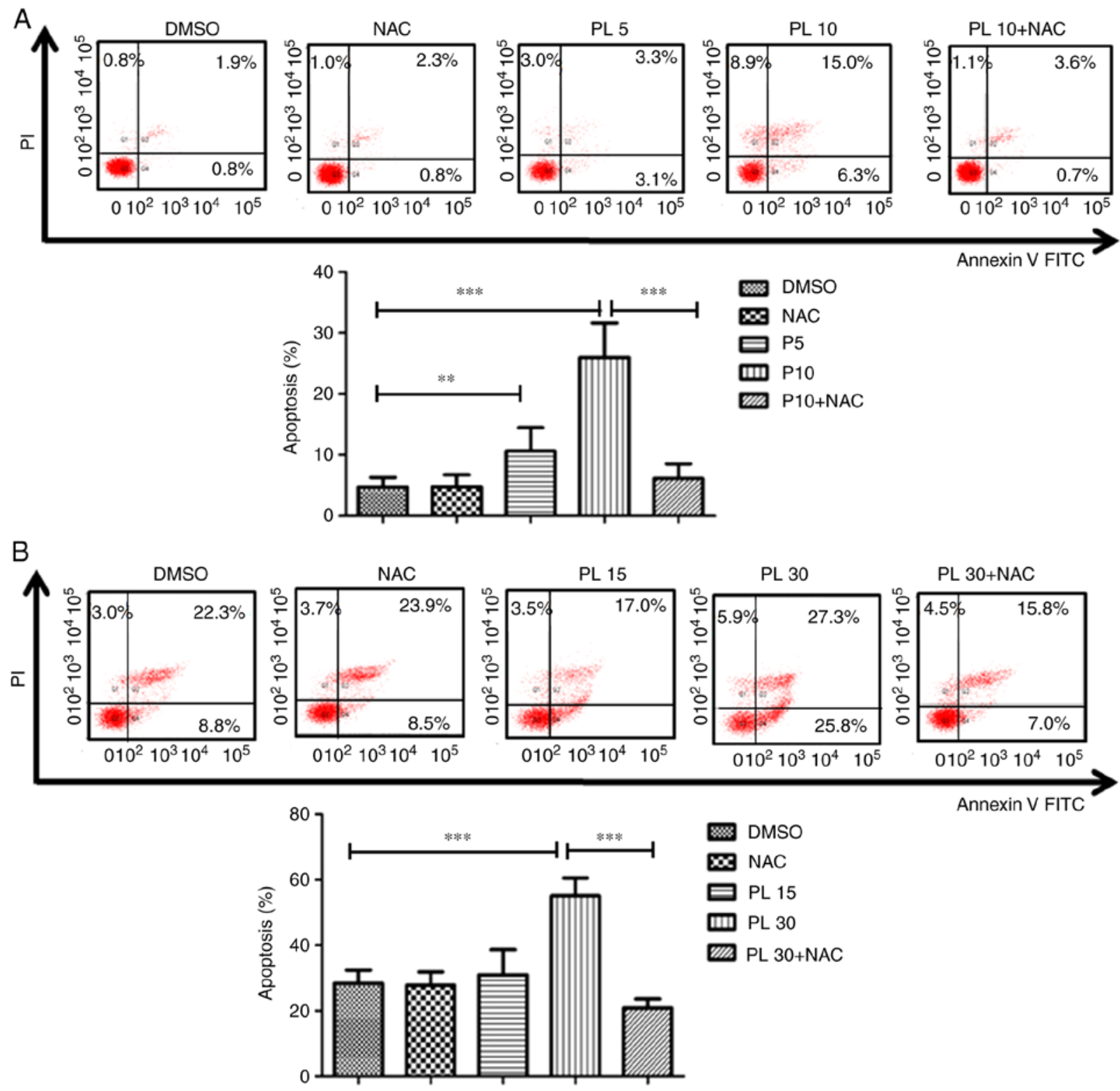

Annexin V FITC

Figure 4. PL induces apoptosis in HuCCT-1 and OCUG-1 cells. (A) HuCCT-1 and (B) OCUG-1 cells were treated with the indicated concentrations of PL for $48 \mathrm{~h}$ with or without NAC pretreatment. Apoptotic cells were determined by PI and Annexin-V staining, and analyzed via flow cytometry. Data are presented as the mean $\pm \mathrm{SD}$ of at least three independent experiments. ${ }^{* *} \mathrm{P}<0.01,{ }^{* * * *} \mathrm{P}<0.001$. PL, piperlongumine; NAC, $N$-acetyl-1-cysteine. 
A

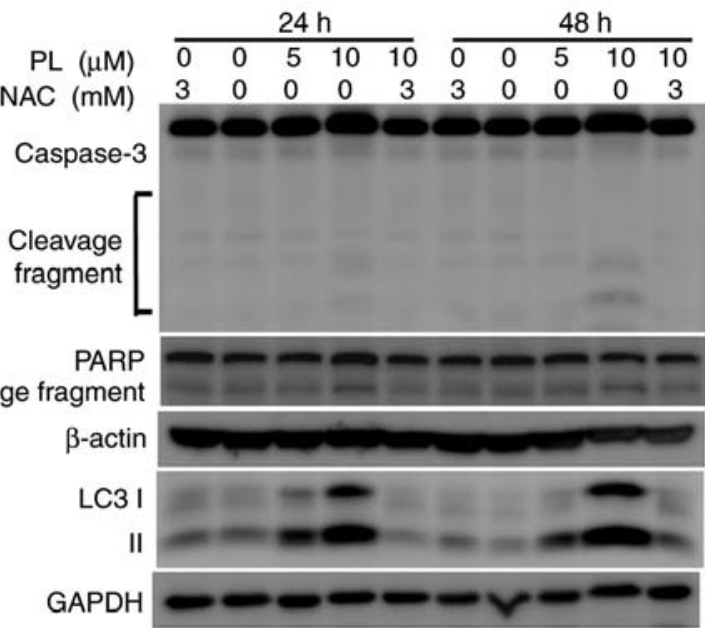

B
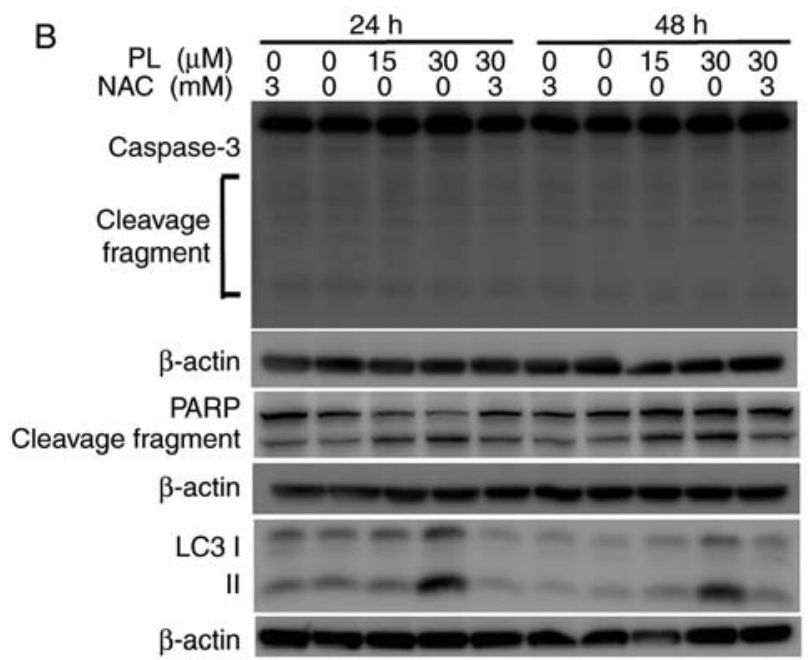

Figure 5. PL induces apoptosis and autophagy related protein expression in HuCCT-1 and OCUG-1 cells. (A) HuCCT-1 and (B) OCUG-1 cells were treated with the indicated concentrations of PL for $48 \mathrm{~h}$ with or without NAC pretreatment. Expression levels of caspase 3, PARP, and LC3 proteins were analyzed by western blotting. LC3, microtubule-associated protein 1A/1B light chain 3B; PARP, poly(ADP-ribose) polymerase; PL, piperlongumine; NAC, $N$-acetyl-1-cysteine.

be detected using immunofluorescence staining. LC-3 puncta were analyzed in PL-treated cells using an LC3-specific antibody. As shown in Fig. 6C, an clear increase in LC-3 puncta was detected after PL treatment, and a decrease with Erk inhibition in pretreated HuCCT-1 cells. These data suggested that PL treatment induces autophagy via ROS-mediated Erk signaling. To further determine whether ROS accumulation was upstream of Erk activation in PL-treated HuCCT-1 cells, an MEK inhibitor, PD98059, was used to analyze ROS levels in PL-treated HuCCT-1 cells. The results of flow cytometry showed that pretreatment with the MEK inhibitor did not affect ROS levels in PL-treated cells (Fig. S2). Then, HuCCT-1 cells were pretreated with PD98059 followed by PL treatment, and apoptosis was analyzed using flow cytometry. The apoptotic cell ratio increased from $13.2 \pm 3.2 \%$ in PL-treated cells to $16.5 \pm 3.0 \%$ in cells pretreated with PD98059 followed by PL application (Fig. 7A). It was hypothesized that if autophagy was blocked by Erk inhibition in PL-treated HuCCT-1 cells, the cells would undergo apoptosis. However, there was no significant difference in the apoptotic rate of HuCCT-1 cells
A

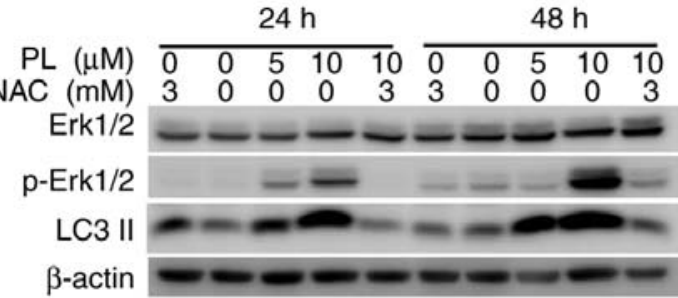

B

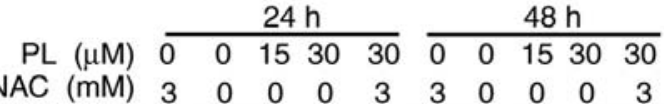
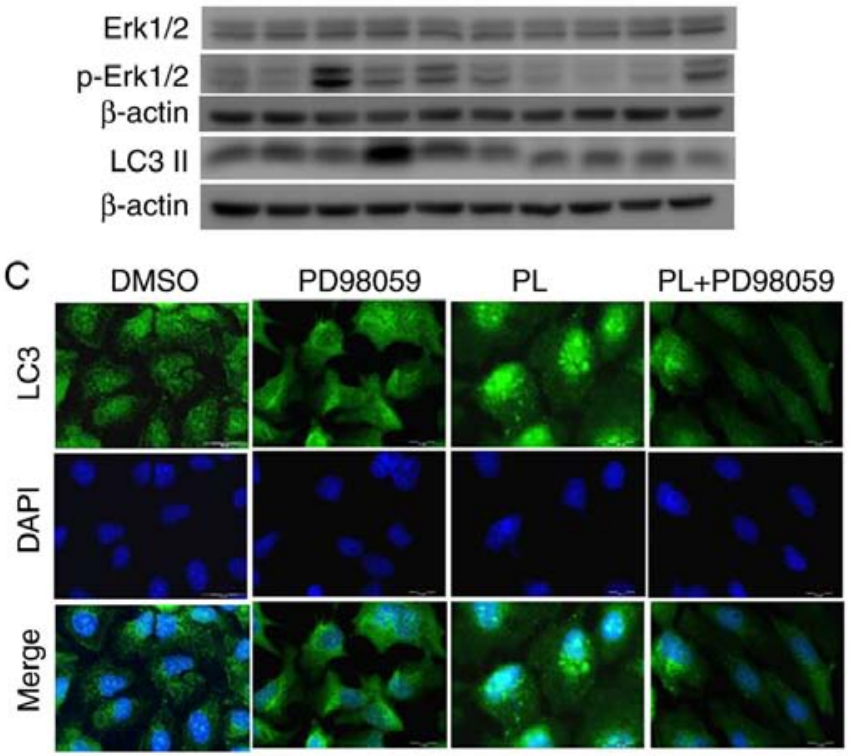

Figure 6. PL induces autophagy in HuCCT-1 and OCUG-1 cells via activation of Erk signaling. (A) HuCCT-1 and (B) OCUG-1 cells were treated with the indicated concentrations of PL for 24 or $48 \mathrm{~h}$ with or without NAC pretreatment. Expression levels of Erk and LC3 proteins were analyzed via western blotting. (C) HuCCT-1 cells were treated with $10 \mu \mathrm{M}$ PL in the presence or absence of the mitogen-activated protein kinase kinase inhibitor PD98059 $(20 \mu \mathrm{M})$ for $24 \mathrm{~h}$. The cells were then fixed and stained with LC3 antibody and analyzed via fluorescence microscopy. LC3, microtubule-associated protein 1A/1B light chain 3B; p, phosphorylated; PL, piperlongumine; NAC, $N$-acetyl-1-cysteine.

with or without pretreatment with PD98059 (Fig. 7A). The expression of apoptosis-associated proteins was detected by western blotting. PD98059 decreased the LC3-II level in PL-treated HuCCT-1 cells, but increased the cleaved forms of caspase 3 and PARP (Fig. 7B). The relative level of LC3-II for each treatment was quantified using a UVP image system. A significant reduction in LC3-II was observed following pre-treatment with a high concentration of PD98059 $(30 \mu \mathrm{M})$ before application of $7.5 \mu \mathrm{M}$ PL to HuCCT-1 cells (Fig. 7C).

\section{Discussion}

$\mathrm{BC}$ represents a heterogeneous malignancy with poor prognosis. Therefore, there is an urgent requirement to develop new drugs for $\mathrm{BC}$ treatment. The aim of the present study was to determine the inhibitory effects of $\mathrm{PL}$ on $\mathrm{BC}$ cell growth. It was found that PL exhibited cytotoxicity in HuCCT-1 and OCUG-1 cells by interfering with redox balance via ROS production. It was also determined that PL induced cell cycle arrest, apoptosis and autophagy via ROS-activated Erk signaling in HuCCT-1 

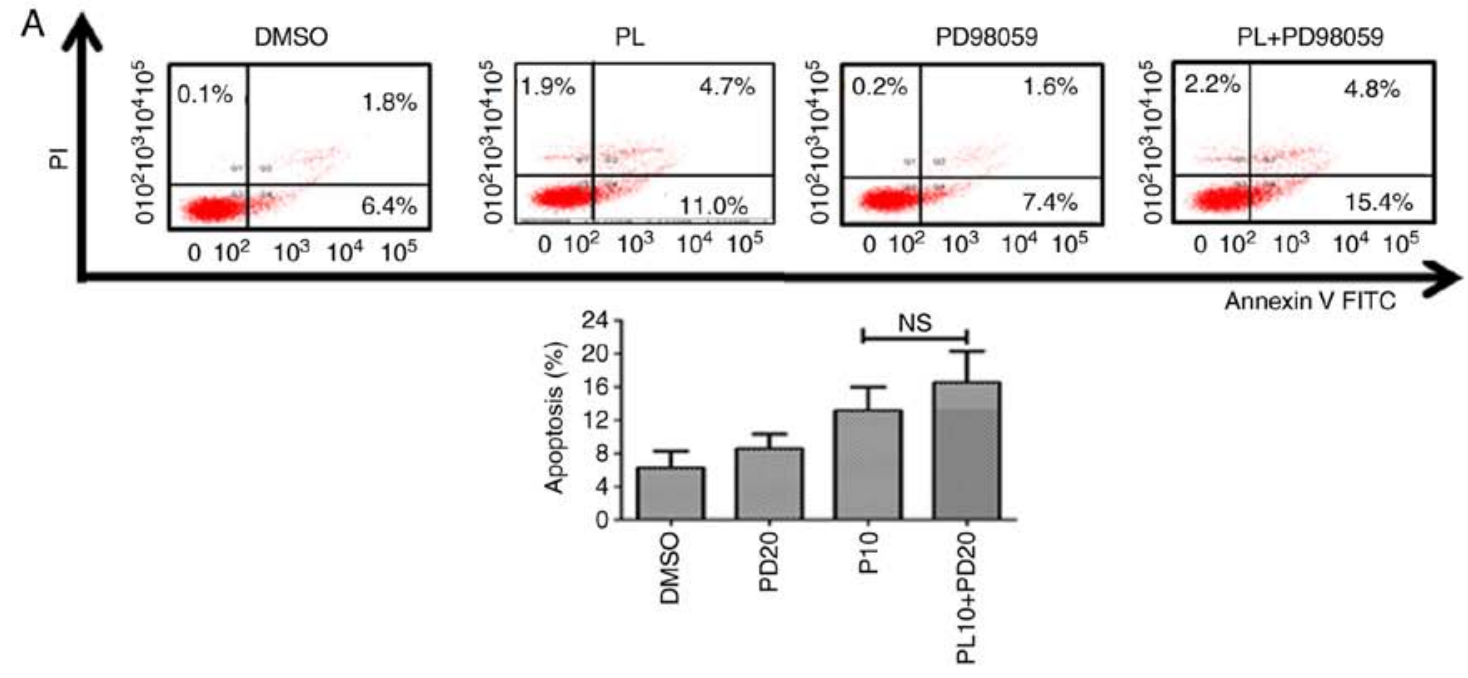

$\begin{array}{lrlcccccccc}\text { B } & \text { PL }(\mu \mathrm{M}) & 0 & 5 & 7.5 & 0 & 5 & 7.5 & 0 & 5 & 7.5 \\ & \text { PD98059 }(\mu \mathrm{M}) & 0 & 0 & 0 & 20 & 20 & 20 & 30 & 30 & 30\end{array}$

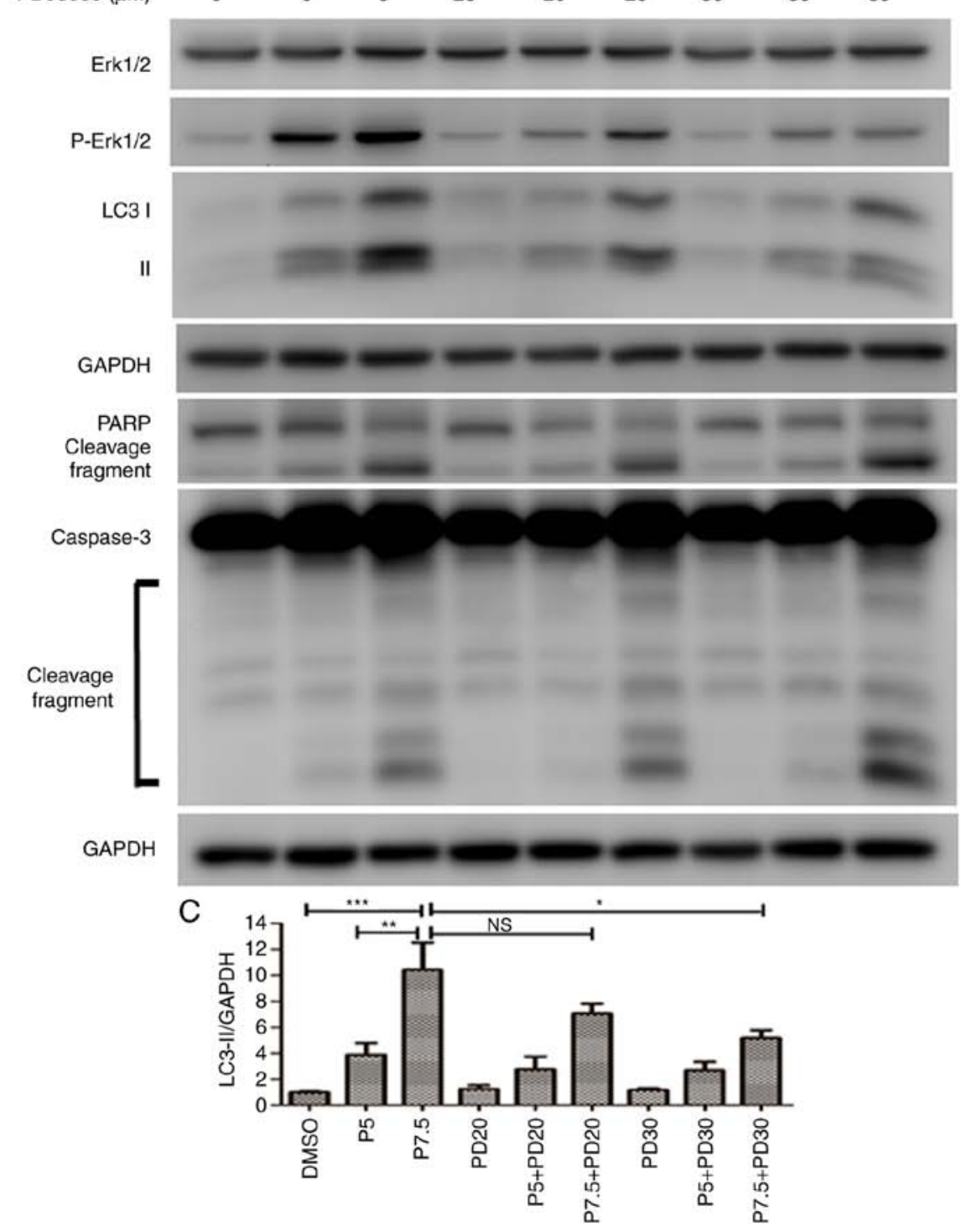

Figure 7. Inhibition of the Erk signaling pathway increases apoptosis in PL-treated HuCCT-1 cells. (A) HuCCT-1 cells were pretreated in the presence or absence of the MEK inhibitor PD98059 (20 $\mu \mathrm{M})$ followed by treated with $10 \mu \mathrm{M}$ PL for $24 \mathrm{~h}$. Apoptotic cells were analyzed by flow cytometry. The x- and y-axes represent the fluorescence intensity of Annexin V-FITC and PI fluorescence in HuCCT-1 cells, respectively. (B) HuCCT-1 cells were treated with 5 or $7.5 \mu \mathrm{M}$ PL in the presence or absence of various concentrations of the MEK inhibitor PD98059 for $24 \mathrm{~h}$. Expression levels of Erk, PARP, LC3 and caspase 3 proteins were analyzed via western blotting. (C) Quantification of LC3-II expression relative to the DMSO control group is presented. Data are presented as the mean $\pm \mathrm{SD}$ of at least three independent experiments. ${ }^{*} \mathrm{P}<0.05,{ }^{* *} \mathrm{P}<0.01,{ }^{* * *} \mathrm{P}<0.001 ;$ n.s., not significant. LC3, microtubule-associated protein $1 \mathrm{~A} / 1 \mathrm{~B}$ light chain 3B; MEK, mitogen-activated protein kinase kinase; p, phosphorylated; PARP, poly(ADP-ribose) polymerase; PI, propidium iodide; PL, piperlongumine. 
cells, and transiently in OCUG-1 cells. The present findings indicated that PL is a potential drug for BC treatment.

Cancer cells are more vulnerable to ROS-mediated effects owing to elevated ROS levels (15). PL inhibits the antioxidant enzyme glutathione S-transferase P, leading to elevated ROS production and subsequently resulting in cancer cell death (29,30). In the present study, it was revealed that PL treatment at lower doses induced ROS production in HuCCT-1 cells, indicating that HuCCT-1 cells were sensitive to PL treatment. The $\mathrm{IC}_{50}$ calculated using a CCK-8 assay supported this hypothesis. HuCCT-1 cells exhibited more sensitive responses than OCUG-1 cells to PL treatment, with $\mathrm{IC}_{50}$ values of 4.2 and $13.8 \mu \mathrm{M}$ at $48 \mathrm{~h}$, respectively. Recently, PL has been shown to exhibit cytotoxicity in other CCA cells (KKU-055, KKU-100, KKU-139, KKU-213 and KKU-214) (31). PL showed similar $\mathrm{IC}_{50}$ values in these cells, ranging between 4 and $20 \mu \mathrm{M}$, suggesting that PL is a potent anticancer drug for treating CCA.

High ROS levels in cells result in cell cycle arrest and subsequent cell death (32). It was demonstrated that PL interfered with cell cycle progression in both HuCCT-1 and OCUG-1 cells. It is proposed that PL may induce G2/M cell cycle arrest in HuCCT-1 cells. Phosphorylation and dephosphorylation of cdc 2 at tyrosine 15 by Wee1 and cdc25, respectively, cooperatively control the cdc2/cyclin B complex and regulate cell cycle entry into mitosis (33). Therefore, phosphorylation of cdc2 at tyrosine 15 is an effective marker of G2/M cycle arrest; however, only the protein expression levels of cdc $25 \mathrm{C}$, cyclin B1, cdc2 and cyclin A2 were analyzed in this study.

The expression levels of antioxidant genes may determine differential responses after PL treatment (31). Thongsom et al (31) determined the mRNA expression levels of five antioxidant genes, including PARK1, TXN, NQO1, $H O-1$ and SOD2, in CCA cells. Among the proteins encoded by these genes, heme oxygenase-1 (HO-1) expression may be a major factor contributing to the antioxidant capacity of CCA cells. Consistent with this finding, HO-1 expression contributed to the differential responses of breast cancer cells to PL treatment (34). HO-1 expression is also inversely associated with survival in patients with CCA (35). The higher antioxidant capacity of OCUG-1 cells may be due to upregulated expression of antioxidant genes compared with HuCCT-1 cells; however, this requires further investigation.

PL was reported to induce apoptosis in CCA cell lines (KKU-055, KKU-100, KKU-139, KKU-213 and KKU-214) (31). In the present study, it was found that PL also induced autophagy in HuCCT-1 and OCUG-1 cells, as indicated by an increase in LC3-II in a concentration-dependent manner. The balance between ROS and autophagy affects cellular homeostasis and survival $(36,37)$. Drugs that induce ROS production may promote cancer cell death by activating autophagy. PL has been reported to induce autophagy in kidney, prostate and breast cancer (23), and leukemia cells (38). The increase in LC3-II was reversed by the application of NAC prior to PL treatment, suggesting that ROS were involved in autophagy induction.

Numerous signaling pathways can be involved in autophagy induction. Previously, it was reported that PL exhibits anticancer activity by affecting PI3K/AKT, p38/JNK, MEK/Erk and $\mathrm{NF}-\kappa \mathrm{B}$ signaling pathways in cancer cells $(24,38-40)$. In the present study, only the Erk pathway was analyzed; it was revealed that the Erk pathway was involved in the anticancer activity of PL in HuCCT-1 cells. Upon inhibition of the Erk signaling pathway, LC3-II expression and puncta levels decreased. Apoptosis was promoted after inhibition of Erk signaling in HuCCT-1 cells. Various molecules have been reported to be involved in the crosstalk between autophagy and apoptosis (41). In the present study, it was not determined as to whether an interaction between autophagy and apoptosis played a role in the effects of PL. Further studies are required to examine the relationship between autophagy and apoptosis following PL treatment in HuCCT-1 cells.

BCs can be divided into intrahepatic and extrahepatic CCA, and gallbladder cancers (3). HuCCT-1 cells were established from malignant cells originating from the intrahepatic bile duct tree, whereas OCUG-1 cells were derived from metastatic peritoneal effusion of gallbladder carcinoma. In the present study, HuCCT-1 and OCUG-1 cells were used to evaluate the cytotoxic effects of PL on BCs. The response of OCUG-1 cells after PL treatment varied from that of HuCCT-1 cells in terms of cell cycle distribution and signaling pathway activation; this may result from their different origins.

In conclusion, it was demonstrated that PL exhibits anticancer activity in HuCCT-1 and OCUG-1 cells. PL treatment interfered with redox balance, and induced apoptosis and autophagy. This is the first report, to our knowledge, showing that PL induced autophagy in BC cells. It was further demonstrated that the Erk signaling pathway was involved in PL-induced autophagy in HuCCT-1 cells. However, this is a preliminary report of the treatment of BC with PL. Further studies, including in vivo animal experiments, should be conducted to determine the efficacy of PL as a treatment of BC.

\section{Acknowledgements}

Not applicable.

\section{Funding}

The present study was supported by the Ditmanson Medical Foundation Chiayi Christian Hospital (grant no. R107-008).

\section{Availability of data and materials}

The datasets used and/or analyzed during the current study are available from the corresponding author on reasonable request.

\section{Authors' contributions}

SYC designed the research and collected the data. HYH performed the experiments. HPL performed experiments and helped with the literature search. CYF designed the study and drafted the paper. All authors read and approved the final manuscript.

\section{Ethics approval and consent to participate}

Not applicable.

\section{Patient consent for publication}

Not applicable. 


\section{Competing interests}

The authors declare that they have no competing interests.

\section{References}

1. Banales JM, Cardinale V, Carpino G, Marzioni M, Andersen JB, Invernizzi P, Lind GE, Folseraas T, Forbes SJ, Fouassier L, et al: Expert consensus document: Cholangiocarcinoma: Current knowledge and future perspectives consensus statement from the European network for the study of cholangiocarcinoma (ENS-CCA). Nat Rev Gastroenterol Hepatol 13: 261-280, 2016.

2. Ghouri YA, Mian I and Blechacz B: Cancer review: Cholangiocarcinoma. J Carcinog 14: 1, 2015.

3. Ahn DH and Bekaii-Saab T: Biliary cancer: Intrahepatic cholangiocarcinoma vs. extrahepatic cholangiocarcinoma vs. gallbladder cancers: Classification and therapeutic implications. J Gastrointest Oncol 8: 293-301, 2017.

4. Blechacz B: Cholangiocarcinoma: Current knowledge and new developments. Gut Liver 11: 13-26, 2017.

5. Rizvi S, Khan SA, Hallemeier CL, Kelley RK and Gores GJ: Cholangiocarcinoma-evolving concepts and therapeutic strategies. Nat Rev Clin Oncol 15: 95-111, 2018.

6. Chun YS and Javle M: Systemic and adjuvant therapies for intrahepatic cholangiocarcinoma. Cancer Control 24 $1073274817729241,2017$.

7. Lee J, Park SH, Chang HM, Kim JS, Choi HJ, Lee MA, Jang JS, Jeung HC, Kang JH, Lee HW, et al: Gemcitabine and oxaliplatin with or without erlotinib in advanced biliary-tract cancer: A multicentre, open-label, randomised, phase 3 study. Lancet Oncol 13: 181-188, 2012.

8. Goff LW, Cardin DB, Whisenant JG, Du L, Koyama T, Dahlman KB, Salaria SN, Young RT, Ciombor KK, Gilbert J, et al: A phase I trial investigating pulsatile erlotinib in combination with gemcitabine and oxaliplatin in advanced biliary tract cancers. Invest New Drugs 35: 95-104, 2017.

9. Uenishi T, Yamamoto T, Takemura S and Kubo S: Surgical treatment for intrahepatic cholangiocarcinoma. Clin J Gastroenterol 7: 87-93, 2014.

10. Sabharwal SS and Schumacker PT: Mitochondrial ROS in cancer: Initiators, amplifiers or an Achilles' heel? Nat Rev Cancer 14: 709-721, 2014

11. Pizzino G, Irrera N, Cucinotta M, Pallio G, Mannino F, Arcoraci V, Squadrito F, Altavilla D and Bitto A: Oxidative stress: Harms and benefits for human health. Oxid Med Cell Longev 2017: 8416763, 2017.

12. Cohen Z, Maimon Y, Samuels N and Berger R: Role of reactive oxygen species in the anticancer activity of botanicals: Comparing sensitivity profiles. Oncol Lett 13: 2642-2648, 2017.

13. Trachootham D, Alexandre J and Huang P: Targeting cancer cells by ROS-mediated mechanisms: A radical therapeutic approach? Nat Rev Drug Discov 8: 579-591, 2009.

14. Moloney JN and Cotter TG: ROS signalling in the biology of cancer. Semin Cell Dev Biol 80: 50-64, 2018.

15. Gorrini C, Harris IS and Mak TW: Modulation of oxidative stress as an anticancer strategy. Nat Rev Drug Discov 12: 931-947, 2013.

16. Lin S, Li Y, Zamyatnin AA Jr, Werner J and Bazhin AV: Reactive oxygen species and colorectal cancer. J Cell Physiol 233: 5119-5132, 2018.

17. Huang H, Xie H, Pan Y, Zheng K, Xia Y and Chen W: Plumbagin triggers ER stress-mediated apoptosis in prostate cancer cells via induction of ROS. Cell Physiol Biochem 45: 267-280, 2018.

18. Zhang L, Li J, Zong L, Chen X, Chen K, Jiang Z, Nan L, Li X, Li W, Shan T, et al: Reactive oxygen species and targeted therapy for pancreatic cancer. Oxid Med Cell Longev 2016: 1616781, 2016.

19. Sharma V, Joseph C, Ghosh S, Agarwal A, Mishra MK and Sen E: Kaempferol induces apoptosis in glioblastoma cells through oxidative stress. Mol Cancer Ther 6: 2544-2553, 2007.

20. Wang C, Lv H, Yang W, Li T, Fang T, Lv G, Han Q, Dong L, Jiang T, Jiang B, et al: SVCT-2 determines the sensitivity to ascorbate-induced cell death in cholangiocarcinoma cell lines and patient derived xenografts. Cancer Lett 398: 1-11, 2017.

21. Möhler H, Pfirrmann RW and Frei K: Redox-directed cancer therapeutics: Taurolidine and Piperlongumine as broadly effective antineoplastic agents (Review). Int J Oncol 45: 1329-1336, 2014.
22. Gong D and Ferrell JE Jr: The roles of cyclin A2, B1, and B2 in early and late mitotic events. Mol Biol Cell 21: 3149-3161, 2010.

23. Makhov P, Golovine K, Teper E, Kutikov A, Mehrazin R, Corcoran A, Tulin A, Uzzo RG and Kolenko VM: Piperlongumine promotes autophagy via inhibition of $\mathrm{Akt} / \mathrm{mTOR}$ signalling and mediates cancer cell death. Br J Cancer 110: 899-907, 2014.

24. Zheng J, Son DJ, Gu SM, Woo JR, Ham YW, Lee HP, Kim WJ, Jung JK and Hong JT: Piperlongumine inhibits lung tumor growth via inhibition of nuclear factor kappa B signaling pathway. Sci Rep 6: 26357, 2016.

25. Sur S and Agrawal DK: Phosphatases and kinases regulating CDC25 activity in the cell cycle: Clinical implications of CDC25 overexpression and potential treatment strategies. Mol Cell Biochem 416: 33-46, 2016.

26. Choi HJ, Fukui M and Zhu BT: Role of cyclin B1/Cdc2 up-regulation in the development of mitotic prometaphase arrest in human breast cancer cells treated with nocodazole. PLoS One 6: e24312, 2011.

27. Georgakilas AG, Martin OA and Bonner WM: p21: A two-faced genome guardian. Trends Mol Med 23: 310-319, 2017.

28. Tanida I, Ueno T and Kominami E: LC3 and autophagy. Methods Mol Biol 445: 77-88, 2008.

29. Harshbarger W, Gondi S, Ficarro SB, Hunter J, Udayakumar D, Gurbani D, Singer WD, Liu Y, Li L, Marto JA and Westover KD: Structural and biochemical analyses reveal the mechanism of glutathione S-Transferase $\mathrm{Pi} 1$ inhibition by the anti-cancer compound piperlongumine. J Biol Chem 292: 112-120, 2017.

30. Piska K, Gunia-Krzyżak A, Koczurkiewicz P, Wójcik-Pszczoła K and Pękala E: Piperlongumine (piplartine) as a lead compound for anticancer agents-Synthesis and properties of analogues: A mini-review. Eur J Med Chem 156: 13-20, 2018.

31. Thongsom S, Suginta W, Lee KJ, Choe H and Talabnin C: Piperlongumine induces $\mathrm{G} 2 / \mathrm{M}$ phase arrest and apoptosis in cholangiocarcinoma cells through the ROS-JNK-ERK signaling pathway. Apoptosis 22: 1473-1484, 2017.

32. Verbon EH, Post JA and Boonstra J: The influence of reactive oxygen species on cell cycle progression in mammalian cells. Gene 511: 1-6, 2012.

33. Perry JA and Kornbluth S: Cdc25 and wee1: Analogous opposites? Cell Div 2: 12, 2007.

34. Lee HN, Jin HO, Park JA, Kim JH, Kim JY, Kim B, Kim W, Hong SE, Lee YH, Chang YH, et al: Heme oxygenase-1 determines the differential response of breast cancer and normal cells to piperlongumine. Mol Cells 38: 327-335, 2015.

35. Kongpetch S, Puapairoj A, Ong CK, Senggunprai L, Prawan A, Kukongviriyapan U, Chan-On W, Siew EY, Khuntikeo N, The BT and Kukongviriyapan V: Haem oxygenase 1 expression is associated with prognosis in cholangiocarcinoma patients and with drug sensitivity in xenografted mice. Cell Prolif 49: 90-101, 2016

36. Chen YF, Liu H, Luo XJ, Zhao Z, Zou ZY, Li J, Lin XJ and Liang Y: The roles of reactive oxygen species (ROS) and autophagy in the survival and death of leukemia cells. Crit Rev Oncol Hematol 112: 21-30, 2017.

37. Azad MB, Chen Y and Gibson SB: Regulation of autophagy by reactive oxygen species (ROS): Implications for cancer progression and treatment. Antioxid Redox Signal 11: 777-790, 2009.

38. Wang H, Wang Y, Gao H, Wang B, Dou Land Li Y: Piperlongumine induces apoptosis and autophagy in leukemic cells through targeting the PI3K/Akt/mTOR and p38 signaling pathways. Oncol Lett 15: 1423-1428, 2018.

39. Chen SY, Liu GH, Chao WY, Shi CS, Lin CY, Lim YP, Lu CH, Lai PY, Chen HR and Lee YR: Piperlongumine suppresses proliferation of human oral squamous cell carcinoma through cell cycle arrest, apoptosis and senescence. Int J Mol Sci 17: pii: E616, 2016.

40. Yamaguchi Y, Kasukabe T and Kumakura S: Piperlongumine rapidly induces the death of human pancreatic cancer cells mainly through the induction of ferroptosis. Int J Oncol 52: 1011-1022, 2018.

41. Su M, Mei Y and Sinha S: Role of the crosstalk between autophagy and apoptosis in cancer. J Oncol 2013: 102735, 2013.

This work is licensed under a Creative Commons Attribution-NonCommercial-NoDerivatives 4.0 International (CC BY-NC-ND 4.0) License. 